\title{
Ethological Assessment of Calves' Welfare According to Weaning Method
}

\author{
Radu I. NEAMȚ ${ }^{\left.1,2^{*}\right),}$ Stelian ACATINCĂI ${ }^{2],}$ Daniela E. ILIE $^{1)}$, Ludovic T. CZISZTER ${ }^{2)}$ \\ 1) Research and Development Station for Bovine, 32 Calea Bodrogului Street, 310059, Arad, Romania \\ ${ }^{2)}$ Department of Animal Production Engineering, Faculty of Animal Science and Biotechnologies, \\ Banat's University of Agricultural Sciences and Veterinary Medicine "King Michael I of Romania", 119 \\ Calea Aradului Street, 300645, Timisoara, Romania \\ *Corresponding author, e-mail: neamtr@yahoo.com
}

Bulletin UASVM Animal Science and Biotechnologies 72(2) / 2015

Print ISSN 1843-5262; Electronic ISSN 1843-536X

DOI:10.15835/buasvmcn-asb:11220

\begin{abstract}
Weaning is a major stress factor for calves. The interruption of milk diet affects the calves' welfare directly due to changes in specific behaviour, and indirectly, due to the effects of the weaning crisis induced. This study was conducted on a herd of 48 calves of Romanian Spotted breed, Flechvieh type. Gradual weaning with a 10-day preweaning period, was applied to a group of 30 calves, while 18 calves were weaned abruptly. Ethological records focused on behavioural patterns such as frequency and intensity of intake, habitat exploration and agonistic behaviour. Data processing, using descriptive statistics model, highlights behavioural differences between these two groups of calves. Gradually weaned calves allocated $7.4 \pm 0.26$ intake bouts/day, totalling $143.56 \pm 5.19 \mathrm{~min} . /$ day, compared with only $5.7 \pm 0.39$ intake bouts/day with a total of $92.34 \mathrm{~min}$./day for abruptly weaned calves $(P<0.001)$. Abrupt weaning significant increased $(P<0.01)$ the frequency of habitat exploration events $(9.4 \pm 1.12 v s 8.2 \pm 0.97$ event/day) and also increased frequency (6.36 \pm 1.19 vs $3.09 \pm 0.23$ events/day) and intensity of agonistic behaviour $(75.68 \pm 6.22 \mathrm{~s} /$ day vs. $22.18 \pm 0.92 \mathrm{~s} /$ day, $P<0.001)$ compared with gradual weaning. Gradual weaning kept levels of stress at low values and decreased the frequency and intensity of unwanted behavioural patterns. Maintaining increased frequencies and intensities of intake behaviour patterns positively influence calves performance with direct effects on future reproductive and productive performance.
\end{abstract}

Keywords: behaviour, calves welfare, weaning method

\section{INTRODUCTION}

Weaning is a key moment in a young animal's life. It represent the survival efforts of a helpless animal from the period of own dam dependence, regarded as a protective element and the only source of food (Broom and Fraser, 2007).

It is known that weaning method exerts major influences on behavioural indices. In specialized farms, weaning is done using two recognized methods, gradual and abrupt weaning. Calves' behavioural response varies according to the weaning method, and it is very easy to predict and maintain for several days post weaning. Primary behaviours (locomotion, exploration, decubital resting or vocalizations) vary in intensity according to the weaning method (Veissier and Neindre, 1989). Calves' behavioural response can be a significant indicator of the stressful effect exerted by the weaning method. Application of certain weaning methods should take account of these reactions, in order to limit its effects.

The maintenance system along with the weaning method can decreases desired behavioural patterns (intake, decubital resting) and increase certain unwanted behaviour (exploratory, agonistic).

Weaning involves changing the calves' diet, habitat, group hierarchy and largely eliminate the 
protection offered by the presence of adult animals. Trying to accommodate to new life conditions, the calves' behaviour changes significantly under the influence of new stressors (Price et al., 2003; Newberry and Swanson, 2008; Weary, 2008). Indicators of stress presence in this period of life are constituted by the physiological response (increased cortisol, Lay et al., 1998) also increased heart rate and behavioural responses (Loberg et al., 2008).

\section{MATERIALS AND METHODS}

The research activities were performed in accordance with the European Union's Directive for animal experimentation (Directive 2010/63/ EU).

The study was carried out at the Arad Research and Development Station for Bovine,

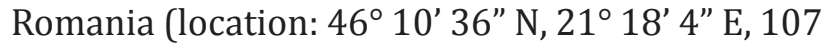
$\mathrm{m}$ altitude, $582 \mathrm{~mm}$ annual average rainfall, $21^{\circ} \mathrm{C} /$ $1^{\circ} \mathrm{C}$ average temperature in summer / winter, with an annual average temperature of $10.5^{\circ} \mathrm{C}$ ).

The animals from this farm were reared in a semi-intensive system, characterized by moderate growth rate in young stock (500-750 g/day) and moderate productive values for lactating cows (5500-6200 kg milk / normal lactation). Productive lifetime for lactating cows averages 5.2 lactations.

Newborn calves were separated from their dam immediately after birth and kept in individual pens up to seven days of age. Individual pens were located within the maternity shed. Between 8 to 90 days of age, calves were kept in small groups (6 heads/group), with free access to the resting area $\left(0.5 \mathrm{~m}^{2} /\right.$ head), moving area $\left(1.1 \mathrm{~m}^{2} /\right.$ head $)$ and watering space $\left(0.03 \mathrm{~m}^{2} /\right.$ head $)$. Colostrum was administered within the first 72 hours of life from their own cows, twice a day every 12 hours. Milk diet was administered in two daily portions, at 12-hour intervals ( 6 am and $6 \mathrm{pm}$ ), $6 \mathrm{~kg} / \mathrm{head} /$ day. The pre-weaning period for gradually weaned calves was set at 10 days (interval 80 to 90 days of age) (Sweeney et al. 2010).

From the 3rd day of life, the calves received forage concentrate. From the 7 th day of life, the calves received alfalfa hay. The experimental herd consisted in 48 Romanian Spotted dual purpose breed, Fleckvieh type calves. A total of 30 calves weaned gradually with a pre-weaning period of 10 days, the remaining 18 calves weaned abruptly, through total ceasing of milk diet in the weaning morning (day 90). Calves were moved in common shelter, with free access to the movement, feeding and watering areas on day 90. Ethological records were performed on the weaning day (24-hour interval).

The statistical processing and data interpretation process aimed to evaluate: i) intake behaviour; ii) exploration behaviour of new habitat; iii) agonistic behaviour.

The behaviour specific patterns studied were analysed through i) frequency of daily events; ii) the average length of an event; iii) total daily length of events.

Data was expressed as means \pm standard errors, using the descriptive statistics model. Differences occurred were tested using Tukey HSD-test (Gavojdian et al., 2015). The level of significance was considered $P \leq 0.05$.

All analyses were performed using Statistica software (StatSoft) version 8 (Hill and Lewicki, 2007).

\section{RESULTS AND DISCUSSION}

Introduction from the first week of vegetal forage is an essential condition for maintaining an optimum $\mathrm{pH}$ level and to avoid ruminal acidosis and negative effects on the calves' general status (Laarman and Oba, 2011; Terre et al., 2013). Data for behavioural patterns included in the present study according to weaning methods applied are given in Table 1.

\section{Intake behaviour}

The influence of the weaning method applied was observable from the analysis of specific behaviour patterns. Abruptly weaned calves presented low values regarding bouts frequency for vegetal forage intake compared to gradually weaned calves ( $5.7 \pm 0.39$ vs. $7.4 \pm 0.26$ bouts/day), at a statistically verified difference $(\mathrm{P}<0.001)$. The gradual weaning method provides calves an additional time for getting used to vegetal forage. Even if these vegetal sorts were introduced in feed ration from the first week of age, calves will opt for milk diet, (milk amount remains at high level and has the ability to provide most of the nutrients needed). Given a reduction in milk, this option decreases gradually, calves being somewhat forced to supplement their nutritional requirements with vegetal sorts. The behaviour of gradually weaned 
Tab. 1 Means ( \pm standard error) for calves` behaviour patterns according to weaning method

\begin{tabular}{|c|c|c|c|c|}
\hline $\begin{array}{l}\text { Weaning } \\
\text { method }\end{array}$ & Parameters & $\begin{array}{c}\text { Intake } \\
\text { behaviour } \\
\text { (min.) }\end{array}$ & $\begin{array}{c}\text { Exploratory } \\
\text { behaviour } \\
\text { (min.) }\end{array}$ & $\begin{array}{c}\text { Agonistic } \\
\text { behaviour } \\
\text { (s) }\end{array}$ \\
\hline \multirow{3}{*}{$\begin{array}{c}\text { Abrupt } \\
\text { weaning } \\
\text { (18 } \\
\text { calves) }\end{array}$} & Events frequency & $5.7 \pm 0.39^{a}$ & $9.4 \pm 1.12^{\mathrm{a}}$ & $6.36 \pm 1.19^{a}$ \\
\hline & Average event length & $16.2 \pm 1.18^{\mathrm{a}}$ & $6.8 \pm 0.28^{\mathrm{a}}$ & $11.9 \pm 0.54^{\mathrm{a}}$ \\
\hline & Total length & $92.34 \pm 2.74^{a}$ & $63.92 \pm 1.14^{\mathrm{a}}$ & $75.68 \pm 6.22^{\mathrm{a}}$ \\
\hline \multirow{3}{*}{$\begin{array}{c}\text { Gradual } \\
\text { weaning } \\
(30 \\
\text { calves) }\end{array}$} & Events frequency & $7.4 \pm 0.26^{b}$ & $8.2 \pm 0.97^{b}$ & $3.09 \pm 0.23^{b}$ \\
\hline & Average event length & $19.4 \pm 1.1^{\mathrm{b}}$ & $5.3 \pm 0.17^{\mathrm{b}}$ & $7.18 \pm 0.19^{\mathrm{b}}$ \\
\hline & Total length & $143.56 \pm 5.19^{b}$ & $43.46 \pm 1.31^{\mathrm{b}}$ & $22.18 \pm 0.92^{\mathrm{b}}$ \\
\hline
\end{tabular}

a,b Columns mean with different superscripts differ significantly at $\mathrm{p} \leq 0.05$

calves with vegetal forage can be seen in the difference in frequency of intake bouts compared to abruptly weaned calves.

On the weaning day, the calves felt acute lack of nutrients from milk, but especially felt a major ethological unfulfillment, constituted in a major stressor factor. The stressor effect of this situation was materialized and could be quantified directly by behavioural studies and indirectly by intake patterns and other adjacent ethological studies, specific for this age category. Both the average length of intake bouts and the total daily length allocated to this behavioural pattern differ significantly $(\mathrm{P}<0.001)$ between these two groups of calves. The average length of intake bouts was higher for gradually weaned calves, $19.4 \pm 1.1$ vs. $16.2 \pm 1.18 \mathrm{~min}$./bout. The total daily length allocated to this activity was significantly increased $(\mathrm{P}<0.001)$ for gradually weaned calves compared to those weaned abruptly. Gradually weaned calves were fed $143.56 \pm 5.19 \mathrm{~min}$./day compared to abruptly weaned calves, which allocated just $92.34 \pm 2.74 \mathrm{~min}$./day. The lower interval allocated for vegetal forage intake by abruptly weaned calves revealed their lack of habit regarding this behaviour. Reducing the feeding interval has serious implications and negative effects on the amount of vegetal forage consumed and therefore on calves` growth performance (Haley et al., 2005).

Gradual weaning is recommended by the results obtained in this study and also by similar studies carried out by different research groups (Khan et al., 2011; de Passille et al., 2011; de Passille and Rushen, 2012).

\section{Exploratory behaviour}

Weaning of calves kept in small groups (6 heads/stall) involve their moving in a common shelters. The new habitat involves obvious behaviour changes (Haley et al., 2005; Enriquez et al., 2009). Calves' moving causes exploratory behaviour patterns. Ethological involvement of these behaviour patterns has significant indirect effects on primary behaviour (intake, orthostatic or decubital resting, locomotion, social behaviour). Calves' curiosity appears when changing environment. On the size of this new environment, the number and nature of the objects that are found around it, also the average stress level charged depend on the intensity and length of specific exploratory behaviour patterns. Thus, gradually weaned calves, whose stress level was lower, showed a reduced daily frequency of exploration events compared to abruptly weaned calves, whose weaning stress exerted a more powerful effect $(8.2 \pm 0.97$ vs. $9.4 \pm 1.12$ events/day) at a statistically significant difference $(\mathrm{P}<0.01)$. The average length of exploratory event and total daily lengths of gradually weaned calves were significantly reduced compared with those abrupt weaned $(\mathrm{P}<0.01)$. Gradually weaned calves had an average length of $5.3 \pm 0.17 \mathrm{~min}$./event compared to those subjected to intense weaning stress, which resulted in a mean of $6.8 \pm 0.28 \mathrm{~min}$./ event, $\mathrm{P}<0.01$. Correlated with exploration bouts frequency, their total daily length was significantly reduced $(\mathrm{P}<0.01)$ compared to gradually weaned calves $(43.46 \pm 1.31$ vs. $63.92 \pm 1.14 \mathrm{~min} /$ day $)$. Abruptly weaned calves showed a high frequency and events length for new habitat exploratory 
behaviour patterns associated with greatly diminished intake behaviour.

\section{Agonistic behaviour}

One of the main indicators of the calves' welfare is their social behaviour, agonistic type. This kind of behaviour occurs in competitive situations (for a place at the feeding trough, watering surface or resting area) or due to actions of a high intensity stress factor. Agonistic behaviour occurred immediately after the calves were moved in a common shelter, due to competitive actions of establishing a new social hierarchy or due to competitive actions as regards primary needs (intake, resting, watering). Specific patterns last 1-3 days (Keeling and Gonzou, 2001), largely depending on technological factors (animals density, feeding space dimensions, drinkers surface, age and weight of animals).

The level of induced stress by abrupt cessation of milk diet, favoured intense and persistent agonistic behaviour patterns among the calves. Ethological recordings performed highlighted a significantly increased $(\mathrm{P}<0.001)$ frequency of agonistic events for abruptly weaned calves $(6.36 \pm 1.19$ events/day) compared to gradually weaned calves $(3.09 \pm 0.23$ events/day). Also, the average length of an agonistic event was significantly higher $(\mathrm{P}<0.001)$ for abruptly weaned calves as compared to those who received pre-weaning period $(11.9 \pm 0.54$ vs. $7.18 \pm 0.19 \mathrm{~s} /$ event). Induced stress level by ceasing the milk diet largely depends on the individual, hence relatively large variations occur in both the frequency and the length of agonistic events. Analysing the daily time budget allocated to agonistic behaviour, we observed statistically significant differences $(\mathrm{P}<0.001)$ between these two groups of calves. Gradually weaned calves allocated a lower time budget for agonistic events (22.18 $\pm 0.92 \mathrm{~s} /$ day) compared to abruptly weaned calves which, under the influence of stress, were more excited and more involved in such events $(75.68 \pm 6.22 \mathrm{~s} /$ day).

\section{CONCLUSION}

The weaning method applied in the farm influences the calves` welfare condition quantified by assessing the behavioural patterns specific to age category.

Correlating data obtained throughout this study, we can conclude that gradually weaned calves record greatly reduced levels of stress compared to abruptly weaned calves. Gradually weaned calves allocated wide intervals of time for intake behaviour. The gradual weaning method offers calves the ability to adjust their eating habits, so that voluntary consumption of vegetal forage is higher compared to abruptly weaned calves. This fact can be seen from the daily time budget analysis, which shows allocation of wide intervals for intake behaviour. Ethological patterns specific for abruptly weaned calves are negatively affected by the weaning method applied. Voluntary vegetal forage intake is greatly diminished, intake behaviour being strongly altered both in frequency and intensity. The level of stress induced by the gradual weaning method is greatly reduced, specific patterns of exploratory and agonistic behaviour having significantly low frequencies and intensities. Abruptly weaned calves recorded higher stress levels, evidenced through higher frequency and intensity of exploratory and agonistic behaviour. Gradual weaning of calves, by ensuring a pre-weaning period of 10 days, provides increased voluntary consumption of vegetal forage, with direct implications on calves` growth performance.

Finally, the gradual weaning method ensures lower stress levels, with occurrences of direct effects on unwanted, especially agonistic behaviour.

Calves`welfare offered by the rearing system constitutes part of the "financial wellbeing" of specific farms activity.

Acknowledgments: This paper was published under the frame of European Social Fund, Human Resources Development Operational Programme 2007-2013, project no. POSDRU/159/1.5/S/ 132765 .

\section{REFERENCES}

1. Broom DM, Fraser AF (2007). Domestic Animal Behaviour and Welfare 4th ed., p. 190., Cambrige University Press, U.K.

2. de Passillé AM, Borderas TF, Rushen J (2011). Weaning age of calves fed a high milk allowance by automated feeders: Effects on feed, water, and energy intake, behavioural signs of hunger, and weight gains. J. of Dairy Sci. 94(3):1401-1408.

3. de Passillé AM, Rushen J. (2012). Adjusting the weaning age of calves fed by automated feeders according to 
individual intakes of solid feed. J. of Dairy Sci. 95(9):52925298.

4. Enríquez DH, Ungerfeld R, Quintans G, Guidoni AL, Hötzel MJ (2010). The effects of alternative weaning methods on behaviour in beef calves. Livest Sci. 128:20-27.

5. Gavojdian D, Budai C, Cziszter LT, Csizmar N, Javor A Kusza S (2015) Reproduction Efficiency and Health Traits in Dorper, White Dorper, and Tsigai Sheep Breeds under Temperate European Conditions. Asian Australas. J. Anim. Sci. 28(4):599-603.

6. Haley DB, Bailey DW, Stookey JM. (2005). The effects of weaning beef calves in two stages on their behavior and growth rate. J Anim Sci. 83:2205-2214.

7. Hill T, Lewicki P (2007). Statistics: Methods and Applications. StatSoft, Tulsa, OK, USA.

8. Keeling JL, Gonzou HW (2001). Social Behavior in Farm Animals, pp. 336-338, British Library, London U.K.

9. Khan MA, Weary DM, von Keyserlingk MA (2011). Invited review: effects of milk ration on solid feed intake, weaning, and performance in dairy heifers. J. of Dairy Sci. 94(3):1071-1781.

10. Laarman AH, Oba M (2011). Effect of calf starter on rumen $\mathrm{pH}$ of Holstein dairy calves at weaning. J. of Dairy Sci. 94(11):5661-5664.
11. Lay DCJr, Friend TH, Randel RD, Bowers CL, Grissom KK, Neuendorff DA, Jenkins OC (1998). Effects of restricted nursing on physiological and behavioral reactions of Brahman calves to subsequent restraint and weaning. Appl Anim Behav Sci. 56:109-119.

12. Loberg JM, Hernandez CE, Thierfelder T, Jensen MB, Berg C, Lidfors L (2008). Weaning and separation in two steps - A way to decrease stress in dairy calves suckled by foster cows. Appl Anim Behav Sci. 111:222-234.

13. Newberry RC, Swanson JC (2008). Implications of breaking mother-young social bonds. Appl Anim Behav Sci. 110:3-23.

14. Price EO, Harris JE, Borgwardt RE, Sween ML, Connor JM (2003). Fenceline contact of beef calves with their dams at weaning reduces the negative effects of separation on behavior and growth rate. J Anim Sci. 81:116-121.

15. Sweeney BC, Rushen J, Weary DM, de Passillé AM (2010). Duration of weaning, starter intake, and weight gain of dairy calves fed large amounts of milk. J. of Dairy Sci. 93(1):148-52

16. Veissier I, Le Neindre P (1989). Weaning in calves: Its effect on social organization. Appl. Anim. Behav. Sci. 24:43-54. 